\title{
Die Flavin-abhängige Fruktosedehydrogenase und Cytochrom c: Elektronentransfer und Sensorstrategien
}

\author{
Christoph Wettstein, Kenji Kano, Daniel Schäfer, Ulla Wollenberger, Fred Lisdat*
}

\section{Zusammenfassung}

Die hier durchgeführten Untersuchungen ermöglichen ein besseres Verständnis der Elektronentransferprozesse zwischen der Flavin-abhängigen Fruktosedehydrogenase (FDH) und dem Redoxprotein Cytochrom c (Cyt c). Dies liefert im Hinblick auf sensorische Anwendungen wichtige Erkenntnisse für vorteilhafte Sensorarchitekturen und deren Messbedingungen. Es wurden zwei unterschiedliche $\mathrm{pH}$-Optima für die Redoxreaktion der beiden Proteine untereinander entdeckt. Die Reaktion wurde im Weiteren mit Elektroden kombiniert und so eine Fruktose-abhängige Stromantwort detektiert. Darüber hinaus konnten definierte dreidimensionale Sensorarchitekturen der beiden Proteine, mit Hilfe von DNA als zusätzlichen biologischen Baustein erzeugt und für die Sensorik genutzt werden.

\section{Abstract}

With regard to sensor application, flavin-dependent fructose dehydrogenase (FDH) and the redox protein cytochrome c (cyt c) were examined for a better understanding of electron transfer (ET) pathways. First, two different $\mathrm{pH}$ optima could be determined for the reaction of both proteins. A fructose-dependent signal can be achieved on a cyt $c$ electrode with adsorbed FDH as well as with the enzyme in solution. Furthermore, fructose sensors could be produced using a defined arrangement of cyt $c$ and FDH by the layer-by-layer technique with DNA as a second building block.

\section{Einleitung}

Elektronentransfer-(ET-)Reaktionen spielen eine entscheidende Rolle in den Stoffwechselprozessen aller Organismen (Berg et al. 2012). Die Reaktionskaskaden der Proteine innerhalb der Atmungskette oder der Photosynthese sind für diese Zwecke optimal angepasst. Es gibt verschiedene Beispiele, in denen versucht wurde, diese Elektronentransferkaskaden zu imitieren, um sie für die analytische Stoffdetektion oder auch für eine bioenergetische Anwendung zu nutzen. In diesem Zusammenhang wurde auch die Elektronenübertragung durch das Redoxprotein Cytochrom $c$ umfassend untersucht. Cytochrom c zeigt einen direkten Elektronentransfer (DET) an modifizierten Elektroden, wie sie bspw. durch Selbstorganisierte Monoschichten (SAM) auf Gold erreicht werden (Taniguchi et al. 1982, Armstrong et al. 1988, Song et al. 1993, Ge et al. 2002). So kann man auf den Einsatz von Redoxmediatoren verzichten, die unter Umständen Interferenzen oder Seitenreaktionen verursachen. Aufgrund des möglichen Selbstaustausches von Elektronen zwischen Cyt c Molekülen gibt es auch verschiedene Ansätze, das Protein in Multischichten anzuordnen (Lisdat et al. 2009, Sarauli et al. 2010, Feifel et al. 2012). Im Hinblick auf sensorische Anwendungen kann Cyt $c$ so genutzt werden, um gekoppelt mit Erkennungselementen, wie bspw. bestimmten Enzymen oder sogar mehreren unterschiedlichen Enzymen auf einer Sensoroberfläche, bioelektrochemische Signale in Abhängigkeit vom Substrat zu generieren (Jin et al. 1996, 1997, Sarauli et al. 2012, Feifel et al. 2014). Hierbei kommen überwiegend voltammetrische Messmethoden zum Einsatz. Gezeigt wurde das bereits für das Flavo-Enzym Cellobiosedehydrogenase (Feifel et al. 2013) und die
PQQ-abhängiger Glukosedehydrogenase (Wettstein et al. 2012). Diese Proteinaufbauten besitzen Potential für Anwendungen in der Bioelektronik, Biosensorik und in Biobrennstoffzellen (Wu et al. 2007, Cooney et al. 2008, Lisdat et al. 2009).

In der hier gezeigten Studie wurde das Hämoflavo-Enzym Fruktosedehydrogenase verwendet. Dies ist ein Membran-assoziiertes Enzym mit einer molaren Masse von ca. 140 kDa. Es besteht aus drei Untereinheiten, von denen die größte ein Flavin-Adenin-Dinukleotid (FAD) und die mittlere Untereinheit drei prosthetische Gruppen Häm c enthält, während die kleinste Untereinheit der Membranassoziierung dient (Ameyama et al. 1981, Kawai et al. 2013, 2014). Die Formalen Potentiale $\left(E_{f}\right)$ der Hämgruppen werden mit $10 \pm 4 \mathrm{mV}, 60 \pm 8 \mathrm{mV}$ und $150 \pm 4 \mathrm{mV}$ vs. $\mathrm{Ag} / \mathrm{AgCl}$ (sat. $\mathrm{KCl}$ ) bei pH 5,0 beschrieben. Werte anderer Studien zeigen das 
Formale Potential adsorbierter FDH an Goldelektroden (+ 80 mV; Kahn et al. 1991) und Kohlenstoffelektroden (+ 39 $\mathrm{mV}$ vs. $\mathrm{Ag} / \mathrm{AgCl}$, sat. $\mathrm{KCl}$; Kamitaka et al. 2007), diese liegen im Bereich des $\mathrm{E}_{\mathrm{f}}$ vom Häm 2, bei $60 \pm 8 \mathrm{mV}$.

Der $\mathrm{K}_{\mathrm{m}}$ Wert des Enzyms für Fruktose wurde mit $10 \mathrm{mM}$ bei $\mathrm{pH} 4,5$ $\left(\mathrm{K}_{3}\left[\mathrm{Fe}(\mathrm{CN})_{6}\right]\right.$ als Elektronenakzeptor) bestimmt (Ameyama et al. 1981). Die $\mathrm{FDH}$ ist ein Enzym mit einem pl von $5,0 \pm 0,1$, sein $\mathrm{pH}$-Optimum liegt bei $\mathrm{pH} \mathrm{4,0}$ bis 4,5 und sein Temperaturoptimum bei $37{ }^{\circ} \mathrm{C}$. Aufgrund hydrophober Oberflächengruppen tendiert FDH in wässriger Lösung zur Präzipitation, was zu einer Inaktivierung des Enzyms führt. Die Lagerung des Enzyms in einem Triton $\mathrm{X}^{\circledR}$-enthaltenden Puffer bei $4{ }^{\circ} \mathrm{C}$ erhält jedoch die Aktivität für mindestens zwei Wochen (Ameyama et al. 1981).

Die FDH wurde in vergangenen Untersuchungen für die Konstruktion von Biosensoren (Kahn et al. 1992, Kinnear et al. 1997, Bassi et al. 1998) sowie für Biobrennstoffzellen (Kamitaka et al. 2007, Tkac et al. 2009, Tamaki et al. 2012) verwendet. Die Immobilisierung konnte gezeigt werden, und sowohl ein Direkter Elektronentransfer (DET) als auch ein Mediator-vermittelter Elektronentransfer (MET) ließen sich nachweisen. Dabei zeigte sich vor allem an kohlenstoffbasierten Materialien die Möglichkeit eines DET (Kamitaka et al. 2007, Tominaga et al. 2007, 2009). Besonders effizienter DET kann beobachtet werden, wenn das Enzym mit der Häm-Untereinheit zur Elektrodenoberfläche ausgerichtet wird. Tominaga et al. (2007) generierten bioelektrokatalytische Ströme auf HOPG (highly oriented pyrolytic graphite, basal-plane) und Kohlenstoffplatten. Die katalytischen Oxidationsströme zeigten sich nur im sauren Milieu ( $\leq \mathrm{pH} 6)$, während im neutralen oder alkalischen Milieu keine katalytischen Reaktionen nachweisbar waren. Hierbei wurde auch eine Zersetzung des FDHTrimers beobachtet. Als effizientestes System zeigt sich bis dato eine kohlenstoffbasierte Elektrode (Ketjen black), deren höchste Stromdichten bei $\mathrm{pH}$ 5 erreicht wurden. Neben Kohlenstoff eignet sich nach vielen Studien auch Gold als mögliche Oberfläche für einen ET von FDH. Beispielsweise können Goldnanopartikel, modifiziert mit Mercaptoethanol, in Anwesenheit von FDH und Fruktose bioelektrokatalytische Signale zeigen (Murata et al. 2009). Auch Polyanilin-modifzierte ITO-Elektroden zeigen einen effizienten DET (Sarauli et al. 2015). Ferapontova et al. (2005) wiesen Reaktionen an Cysteamin- und Mercaptoethanolmodifizierten Goldelektroden nach, mit FDH und Cyt $c$ als Mediator (beides in Lösung). Hier wird ein $\mathrm{pH}$ von 7 als besonders effizient genannt.

Die im Folgenden gezeigten Untersuchungen wollen den Interprotein-ET zwischen FDH und Cyt $c$ sowohl in Lösung als auch mit auf Elektroden gebundenem Protein charakterisieren. Dies hat das Ziel, die Gestaltung von ET-Ketten für analytische Fragestellungen zu ermöglichen, in deren Folge substratspezifische Sensoren (Fruktose) mit einstellbarer Sensitivität erzeugt werden können.

\section{Material und Methoden}

\section{Chemikalien}

Citronensäure, D-Fruktose, Eisen(III)sulfat, Kaliumhexacyanoferrat (III), Kalimhydroxid, 11-Mercapto-1-undecanol (MU), 11-Mercaptoundecansäure (MUA), Triton $X^{\circledR}-100$ (TX), Cytochrom c (Horse heart) und dsDNA (Calf thymus) wurden von SigmaAldrich (Taufkirchen, Germany) bezogen. Ethanol, Natriumdodecylsulfat (SDS), $\mathrm{Na}_{2} \mathrm{HPO}_{4}, \mathrm{H}_{2} \mathrm{SO}_{4}(96 \%), \mathrm{H}_{3} \mathrm{PO}_{4}$ $(\geq 85 \%), \mathrm{H}_{2} \mathrm{O}_{2}(30 \%)$ und $\mathrm{HNO}_{3}(\geq$ $65 \%)$ wurden bei Carl Roth (Karlsruhe, Germany) erworben, $\mathrm{KCl}$ and $\mathrm{K}_{2} \mathrm{HPO}_{4} / \mathrm{KH}_{2} \mathrm{PO}_{4}$ bei der Firma Merck bestellt. Golddraht (0,5 mm Durchmesser, 99,999 \% Reinheit) wurde bei der Firma Goodfellow (Bad Nauheim, Germany) bestellt. Amicon ${ }^{\circledR}$ Ultra Zentrifugalfilter mit einem MWCO von 10 kDa wurden über Merck Millipore Ltd. (Cork, Ireland) bezogen. Alle Lösungen wurden mit $18 \mathrm{M} \Omega$ Reinstwasser hergestellt (Evoqua Water Technologies $\mathrm{GmbH}$, Germany, Ultra Clear Direct).

Kommerziell erhältliche lyophilisierte und mit Stabilisierungsagenzien versehene FDH (Gluconobacter japonicus, NBRCA3260, vorher Gluconobacter industrius) wurde über Sigma Aldrich bezogen (4,5 mg FDH enthielten $5,1 \%$ Protein). Eine 0,5 mg (Protein)/ ml Stammlösung ( $\triangleq$ 3,3 $\mu \mathrm{M}$ ) wurde durch Lösen des Lyophilisats in 0,5 ml Mcllvaine-Puffer ( $\mathrm{pH} 4,5)$ hergestellt. Alternativ wurde FDH (Gluconobacter japonicas, NBRCA3260) aus der Arbeitsgruppe von Prof. Dr. Kenji Kano (Kyoto University, Japan) bezogen. Das Enzym wurde rekombinant in Gluconobacter oxydans expremiert und nach Kawai et al. (2013) aufgereinigt. Es war in einer Stammlösung mit einer Konzentration von $5,6 \mathrm{mg} / \mathrm{ml}$ in $100 \mathrm{mM}$ Mcllvaine-Puffer ( $\mathrm{pH} \mathrm{6,0)} \mathrm{gelöst} \mathrm{und}$ enthielt zur Stabilisierung 300 mM Saccharose. Die Aktivität wurde nach Ameyama et al. (1981) vor der Verwendung bestimmt. Der Aktivitätstest basiert auf der Reduktion von Hexacyanoferrat (III) durch FDH in Anwesenheit von Fruktose. Die Reaktion wird gestoppt durch die Zugabe von Phosphorsäure, SDS und Eisen(III)-sulfat. Dabei denaturiert SDS das Enzym, wodurch die weitere Reduktion des Hexacyanoferrats unterbunden ist. Eisen(III)-sulfat reagiert mit dem Reaktionsprodukt der Reduktion, dem Hexacyanoferrat (II), zu Preußischblau, welches spektroskopisch bei einer Wellenlänge von $660 \mathrm{~nm}$ gemessen werden kann.

UV-Vis-Spektroskopie. Kinetische Messungen wurden mit einem Thermo-Scientific-Evolution-300-Spektrometer (Weltham, MA, USA) durchgeführt. Es wurden je $1 \mathrm{U}$ FDH zu $25 \mu \mathrm{M}$ Cyt c-Lösung, in $100 \mathrm{mM}$ McllvainePuffern bei verschiedenen $\mathrm{pH}$-Werten hinzugegeben. Jede Probe wurde vor der Messung durch Rühren für $5 \mathrm{~s}$ gemischt und für 5 min bei $37^{\circ} \mathrm{C}$ equilibriert. Nachfolgend wurde Fruktose zur Cyt c/FDH-Mischung zugegeben, so dass sich eine Konzentration von 50 $\mathrm{mM}$ einstellte. Die Mischung wurde erneut für $5 \mathrm{~s}$ gerührt. Anschließend wurde die Reduktionsrate von Cyt $c$ durch Aufzeichnung der spektroskopischen Veränderung bei einer Wellenlänge von $550 \mathrm{~nm}$ für 5 min ermittelt. Für die Abschätzung der Reduktionsrate des Cyt $c$ wurde die Geschwindigkeit aus der Anfangssteigung der kinetischen Kurve, innerhalb der linearen Phase und unter Subtraktion der Kontrollwerte (Messung ohne Substratzugabe) berechnet. Unter Verwendung des Lambert-Beer-Gesetzes sowie eines Extinktionskoeffizienten $(\varepsilon)$ für reduziertes Cyt $c$ von $\varepsilon_{(550) \text { red }}-\varepsilon_{(550) \text { ox }}=$ 
21,1 $\mathrm{mM}^{-1} \mathrm{~cm}^{-1}$ (van Gelder) und einer Schichtdicke von $1 \mathrm{~cm}$ konnte die umgewandelte Substratkonzentration ermittelt werden. Als Kontrolle diente die Absorption von vollständig reduzierten Cyt c, welche durch die Zugabe von Ascorbinsäure erhalten wurde.

Präparation der Proteinelektroden. Golddrahtelektroden (AuE) wurden $3 \mathrm{x}$ in frischer Piranhalösung $\left(\mathrm{H}_{2} \mathrm{SO}_{4} /\right.$ $\mathrm{H}_{2} \mathrm{O}_{2}, 3: 1$ ) für 20 min gereinigt. Jedem Schritt folgt eine kurz Ultraschallbehandlung und gründliches Spülen mit Reinstwasser. Anschließend wurden die Elektroden für $4 \mathrm{~h}$ in $2,5 \mathrm{M} \mathrm{KOH}$ gekocht und nach Spülen in Reinstwasser in $96 \%$ iger $\mathrm{H}_{2} \mathrm{SO}_{4}$ gelagert.

Für die Modifizierung mit einer SAM aus MU/MUA wurden Elektroden für $20 \mathrm{~min}$ in $65 \% \mathrm{HNO}_{3}$ gereinigt und mit Reinstwasser, gefolgt von $\mathrm{EtOH}$ (reinst), gespült. Nachfolgend wurde jede Elektrode in einer 3:1-Mischung aus $5 \mathrm{mM} \mathrm{MU}$ und MUA (ethanolische Lösung) für mindestenst $24 \mathrm{~h}$ inkubiert. MU und MUA bilden eine Selbstorganisierte Monoschicht (SAM) auf der Elektrodenoberfläche. Die negativ geladenen Carboxylsäuregruppen binden adsorptiv positiv geladene Cyt c-Moleküle, in einem neutralen $\mathrm{pH}-\mathrm{Be}$ reich, während $\mathrm{MU}$ als Abstandshalter zwischen den MUA-Molekülen dient, um die Dichte der negativ geladenen MUA-Moleküle zu reduzieren (Ge et al. 2002).

Präparation von Cyt c-Monoschichtelektroden. Cyt c-Monoschichten wurden durch zyklovoltammetrische Messung (Scanrate $100 \mathrm{mV} / \mathrm{s}$ ) einer MU:MUA-modifizierten Elektrode in 30 MM Cyt c-Lösung (5 mM KPP pH 7,0) erzeugt.

Präparation von Cyt c-Monoschichtelektroden mit immobilisierter FDH. Cyt c-Monoschichtelektroden wurden wie zuvor beschrieben hergestellt und anschließend in einer $200 \mu \mathrm{g} / \mathrm{ml} \mathrm{FDH-}$ Lösung in 5 mM KPP-Puffer pH 7,0 inkubiert. Da FDH-Stammlösungen im Mcllvaine-Puffer mit zusätzlichen Stabilisierungsagentien vorlagen, wurde die Lösung mit Hilfe von AmiconZentrifugenfiltern (MWCO 10 kDa) umgepuffert (Protokoll nach Herstellerangaben). Präparierte Cyt $c / F D H-$ Elektroden wurden vor der Messung gründlich $5 \mathrm{x}$ in $5 \mathrm{mM}$ KPP-Puffer $\mathrm{pH}$ 7,0 gespült.

Präparation von Cyt c/FDH-Multischichtelektroden. Es wurden verschiedene Mischungen aus 20 MM Cyt $c$ und $\mathrm{FDH}$ mit Konzentrationsverhältnissen von $100: 1$ bis zu $5: 1$ in $0,5 \mathrm{mM}$ KPP-Puffer pH 5,0 hergestellt. Auch die hier verwendeten FDH-Stammlösungen wurden wie zuvor mit AmiconZentrifugenfiltern umgepuffert.

Auf frisch präparierte Cyt c-Monoschichtelektroden wurden durch wechselnde 10-minütige Inkubation in 0,2 $\mathrm{mg} / \mathrm{ml}$ DNA (0,5 mM KPP-Puffer $\mathrm{pH}$ $5,0)$ und oben genannte Cyt $c / F D H$ Mischungen Multischichtarchitekturen erzeugt. Die Elektroden wurden zwischen jedem Immobilisierungsschritt $5 \times$ mit 0,5 mM KPP-Puffer $\mathrm{pH}$ 5,0 gespült. Zur Stabilisierung der Multischichtarchitektur wurden modifizierte Elektroden bei Raumtemperatur getrocknet und anschließend bei $40^{\circ} \mathrm{C}$ für $40 \mathrm{~min}$ in 0,5 mM KPP-Puffer $\mathrm{pH} \mathrm{5,0} \mathrm{inkubiert} \mathrm{(Kepplinger} \mathrm{et} \mathrm{al.}$ 2011).

Zyklovoltammetrie. Zyklovoltammetrische Messungen wurden mit einem Autolab PGSTAT 20 (Metrohm, Germany) durchgeführt. Präparierte Elektroden (Arbeitselektrode) wurden in einer selbstkonstruierten 1-ml-Messzelle bei einer Eintauchtiefe von $2 \mathrm{~mm}$ ( $\hat{=} 3,3$ $\mathrm{mm}^{2}$ aktive Elektrodenoberfläche) vermessen. Als Referenzelektrode diente eine $\mathrm{Ag} / \mathrm{AgCl}$ in $1 \mathrm{M} \mathrm{KCl}$ (Microelectrodes Inc., Bedford, USA) mit einem Potential von $+236 \mathrm{mV}$ vs. NHE (Bard et al. 2007). Als Gegenelektrode diente ein Platindraht mit einer Oberfläche von ca. $50 \mathrm{~mm}^{2}$.

Zur Bestimmung der elektroaktiven Menge Cyt $c$ wurden Zyklovoltammogramme der präparierten Elektroden in $5 \mathrm{mM} \mathrm{KPP-Puffer} \mathrm{pH}$ 7,0 bei einer Scanrate von $100 \mathrm{mV} / \mathrm{s}$ durchgeführt. Dem Faraday-Gesetz folgend korreliert die Ladung (Flächenintegral des Peaks) mit der Anzahl an Redoxmolekülen (Cyt c). Präparierte Elektroden wurden vor der Vermessung im jeweiligen Messpuffer für 2 min equilibriert, im Falle der wärmestabilisierten Multischichtelektroden für $10 \mathrm{~min}$.

Messungen nach Zugabe von Substrat oder freiem Enzym erfolgten immer nach 30-sekündiger Durchmischung der Lösung durch Rühren. Dargestellte Zyklovoltammogramme sind immer zweite Scans. Wenn nötig, sind weitere Scans zur Beurteilung der Stabilität durchgeführt worden.

SPR-Messungen. Messungen der Surface-Plasmon-Resonance (SPR) erfolgten mit einem Biacore T100 (GE Healthcare) bei einer fixen Flussrate von $1 \mu \mathrm{l} / \mathrm{min}$ und einer Temperatur von $25{ }^{\circ} \mathrm{C}$. Goldsensor-Chips (SIA KitAu, BT-1004-0, GE Healthcare) wurden zunächst $3 \times$ für 10 min in frischer Piranhalösung (3:1-Mischung aus 96 \%iger $\mathrm{H}_{2} \mathrm{SO}_{4}$ und $30 \%$ iger $\mathrm{H}_{2} \mathrm{O}_{2}$ ) gereinigt und anschließend mit Reinstwasser und Ethanol (reinst) gespült. Die gereinigten Goldsensorchips wurden analog zu Golddrahtelektroden (siehe oben) mit einer SAM-Schicht aus MU/MUA versehen. Abweichend von der Präparation der Golddrahtelektroden wurden die Schritte des Cyt c-Monoschichtaufbaus und des Multischichtaufbaus aus einer DNA sowie einer Cyt c/FDH-Lösung, unter Einhalten der Konzentrations- und Pufferbedingungen, im Fließsystem mit oben genannter Flussrate durchgeführt. Hierbei konnte mittels SPR-Messungen die Kinetik der Massenzunahmen durch die Modifizierungsschritte verfolgt werden.

\section{Ergebnisse und Diskussion}

Untersuchungen zu Cyt $c$ und FDH in Lösung. Die Elektronentransferreaktion zwischen Cyt $c$ und FDH wurde, durch Bestimmung der Reduktionsgeschwindigkeit von Cyt $c$, im Bereich zwischen $\mathrm{pH}$ 4,5 und 7,0 untersucht. Im Zeitraum der Verfolgung der Absorptionsänderung von Cyt $c$ konnte keine Sättigung der Absorption beobachtet werden. Dies bestätigt, dass die kinetischen Daten im linearen Bereich der Reaktion ermittelt wurden.

Abb. 1 sind die einzelnen Reduktionsgeschwindigkeiten für den untersuchten $\mathrm{pH}$-Bereich zu entnehmen. Man erkennt bei pH 4,0 die höchste Geschwindigkeit und damit den effizientesten Elektronentransfer. Im Weiteren ist eine Abnahme mit zunehmenden $\mathrm{pH}$-Werten festzustellen, jedoch kommt es bei pH-Werten oberhalb von $\mathrm{pH}$ 6,0 wiederum zu einer Zunahme der Reaktionsgeschwindigkeit. 


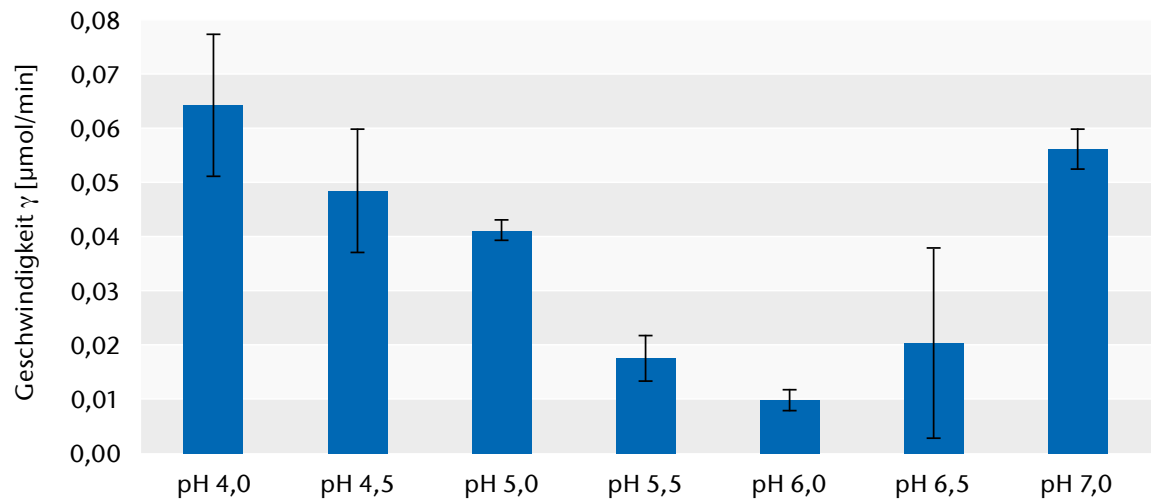

Abb. 1) Geschwindigkeit der Cyt c-Reduktion in Anwesenheit von FDH und Fruktose in Lösung bei unterschiedlichen $\mathrm{pH}$-Werten (100 mM Mcllvaine-Puffer, Cyt $c=25 \mu \mathrm{M}, \mathrm{FDH}=1 \mathrm{U} / \mathrm{ml}$, Fruktose $=50 \mathrm{mM})$. Hier verwendet: kommerzielle FDH (Sigma Aldrich). Mittelwerte aus 3 Wiederholungsmessungen $(n=3)$.

Dies steht im Kontrast zum Verhalten des Enzyms (FDH) mit dem Elektronakzeptor Hexacyanoferrat (III). Hier konnte nur im sauren Medium eine hohe Enzymaktivität festgestellt werden, während im neutralen $\mathrm{pH}$ lediglich 4\% der Aktivität beobachtet wurden (Ameyama et al. 1981). Dass für die Reaktion der FDH mit Cyt $c$ ein weiterer $\mathrm{pH}$-Bereich mit hoher Enzymaktivität gefunden werden konnte, impliziert unterschiedliche Mechanismen in der Interaktion der beiden Moleküle. Zum einen kann der ET über die FAD enthaltende Untereinheit und dann weiter über die Häm enthaltende Untereinheit zum Cyt c erfolgen. Zum anderen besteht die Möglichkeit des direkten ET von der FAD-Untereinheit auf Cyt c. Eine ähnliche Schlussfolgerung ziehen auch Feropontova et al. (2005) aus ihren zyklovoltammetrischen Untersuchungen der FDH mit Cyt $c$ bei verschiedenen Scanraten. Auch hier wurde im neutralen $\mathrm{pH}$ Bereich eine überraschend hohe FDHAktivität beobachtet.

Untersuchungen der Reaktion von oberflächengebundenem Cyt $c$ mit FDH in Lösung. Neutraler pH: Da der heterogene ET von Cyt $c$, gebunden an SAM-Schichten aus MU/MUA, bereits hinreichend charakterisiert und als schnell eingestuft worden ist (Ge et al. 2002), wurde hier direkt mit einer Cyt c-Monoschichtelektrode begonnen, die Reaktion des Redoxproteins mit FDH zu untersuchen. Die Reaktion der beiden Moleküle zeigte bereits in Lösung einen effizienten ET bei pH 7,0. Ausgehend von dieser Erkenntnis wurden substratabhängige zyklovoltammetrische Messungen durchgeführt.
Während Cyt $c$ adsorptiv immobilisiert auf einer MU/MUA-Golddrahtelektrode vorlag, wurden der Messlösung nacheinander FDH sowie zunehmende Konzentrationen Fruktose zugegeben. Abb. 2 sind die daraus resultierenden, substratabhängigen katalytischen Ströme zu entnehmen. Die Katalyse startet bei einem Potential von $-50 \mathrm{mV}$ (vs. $\mathrm{Ag} / \mathrm{AgCl}, 1 \mathrm{M} \mathrm{KCl}$ ) und zeigt eine effiziente Reduktion des Cyt $c$ durch $\mathrm{FDH}$, obwohl es oberflächengebunden nur eingeschränkt zugänglich ist. Die Auftragung der katalytischen Ströme (Abb. 2 B) ergibt eine typische enzymatische Reaktionskinetik vom Michaelis-Menten-Typ. In Näherung kann ein apparenter Km-Wert von 0,5 $\mathrm{mM}$ bestimmt werden.

Darüber hinaus zeigt sich eine Abhängigkeit der biokatalytischen Reaktion von der Konzentration der FDH in Lösung (Ergebnisse hier nicht grafisch dargestellt).

Diese Untersuchungen wurden sowohl mit der kommerziell erhältlichen als auch der nicht kommerziellen FDH vorgenommen. Beide Enzymchargen zeigten ein ähnliches Verhalten, mit einer leicht höheren Aktivität zugunsten der nicht kommerziellen Enzymcharge. Nach Ameyama et al. (1981) wird $\mathrm{FDH}$ in Abwesenheit von stabilisierenden Detergenzien durch Präzipitation inaktiviert. Daher wurden hier Vergleichsmessungen mit und ohne

A

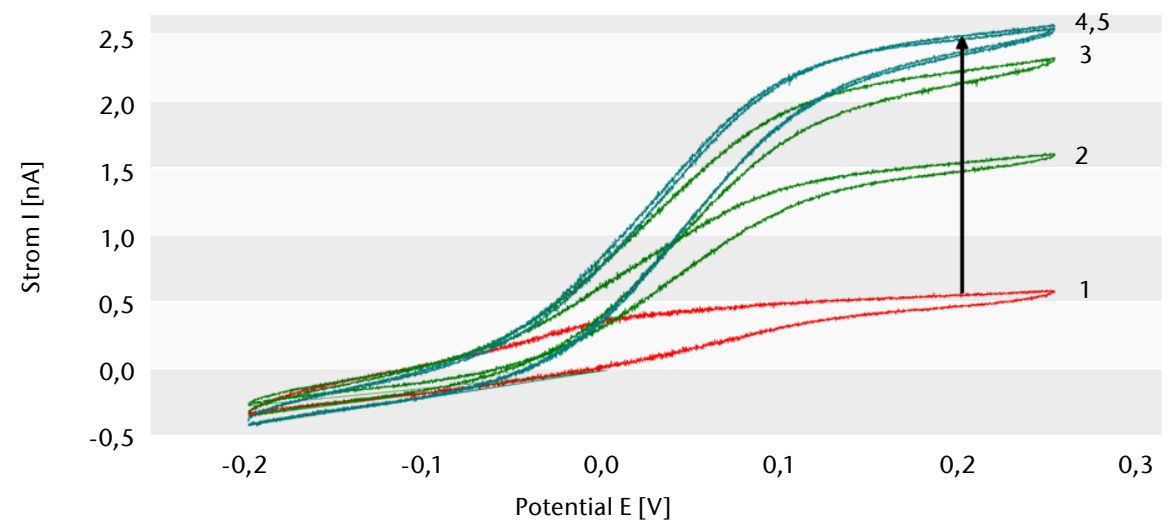

B

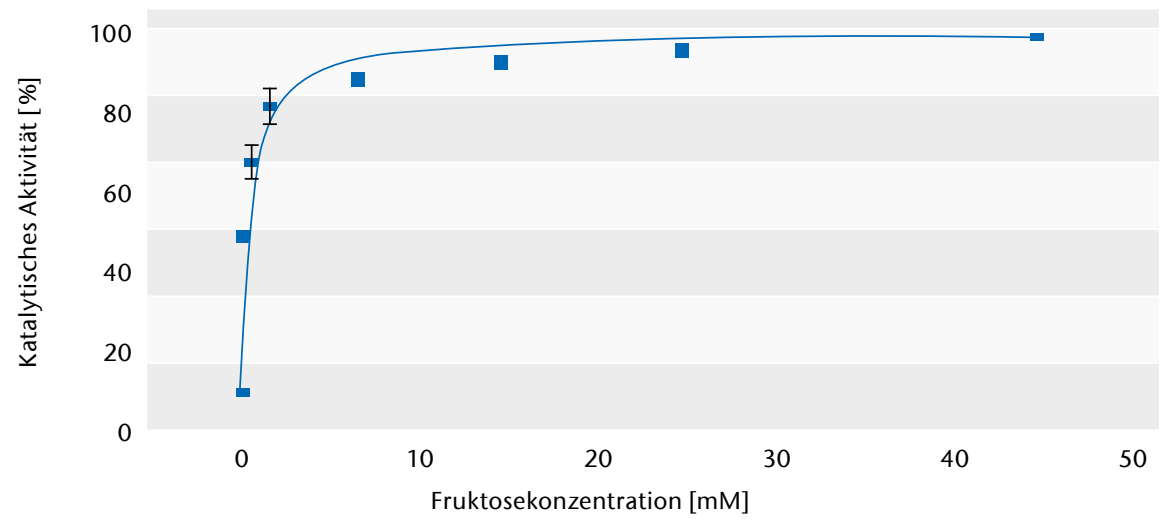

Abb. 2) Zyklovoltammogramme einer Cyt c-Monoschicht-Elektrode in Anwesenheit von $4 \mathrm{U} / \mathrm{ml} F D H$ in Lösung ( $5 \mathrm{mM}$ KPP-Puffer $\mathrm{pH} 7,0$, Scanrate $2 \mathrm{mV} / \mathrm{s}$ ). (A) Cyt c-Monoschicht mit FDH (1) nach Zugabe von FDH und Fruktose unterschiedlicher Konzentrationen: 1,0 mM (2), 6,6 $\mathrm{mM}$ (3), 14,6 mM (4), 24,6 mM (5). (B) Plot der prozentualen katalytischen Stroms gemessen bei $+200 \mathrm{mV}$ (vs. Ag/AgCl, $1 \mathrm{M} \mathrm{KCl}$ ) als Funktion der Fruktosekonzentration. Hier verwendet: nichtkommerzielle FDH aus der AG Kano. Mittelwerte aus 3 Wiederholungsmessungen $(n=3)$. 
das nichtionische Detergens Triton X-100 (TX) durchgeführt (Ergebnisse hier nicht grafisch dargestellt). Dabei konnte nach Zugabe von 0,1 \% TX eine deutliche Abnahme des katalytischen Stroms beobachtet werden. Um zusätzliche Einflussfaktoren auf die Protein-Protein-Interaktion auszuschließen, wurde daher für die nachfolgenden Untersuchungen zum ET-Mechanismus auf eine zusätzliche Zugabe von TX verzichtet.

Saurer $\mathrm{pH}$ : Sowohl die eigenen Untersuchungen zur Reaktion der FDH mit Cyt $c$ in Lösung als auch zuvor publizierte Daten zeigen das $\mathrm{pH}$-Optimum im sauren $\mathrm{pH}$-Bereich zwischen $\mathrm{pH}$ 4,0 und 4,5. Untersucht man den ET von immobilisiertem Cyt $c$ mit FDH in Lösung, stellt man jedoch erst ab $\mathrm{pH}$ Werten von $\mathrm{pH}$ 5,0 eine signifikante katalytisch Aktivität fest (Abb. 3).

Ein eindeutiges und konzentrationsabhängiges katalytisches Signal kann hier beobachtet werden, jedoch ist es deutlich geringer als das, was bei

A

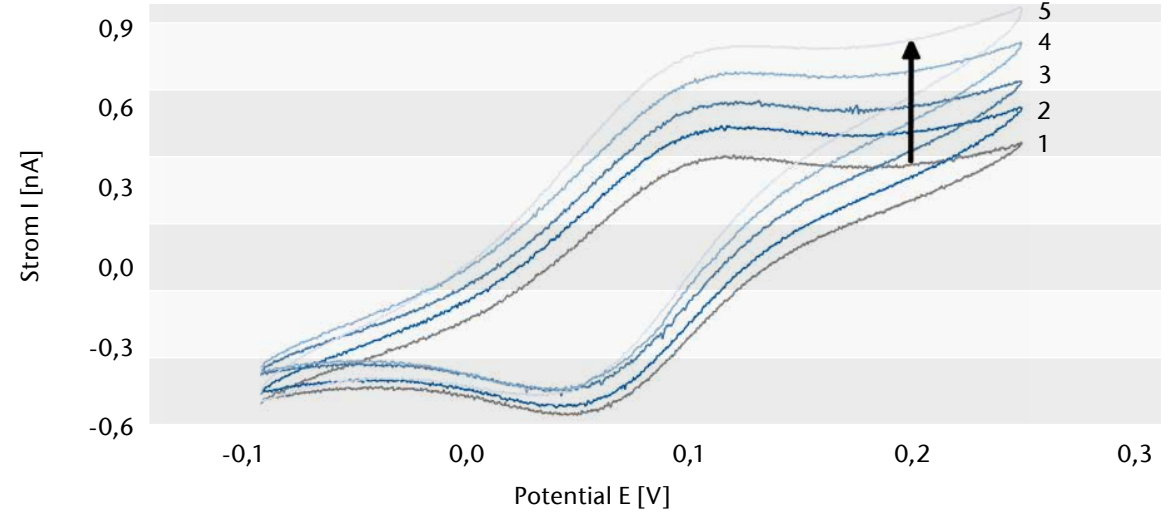

B

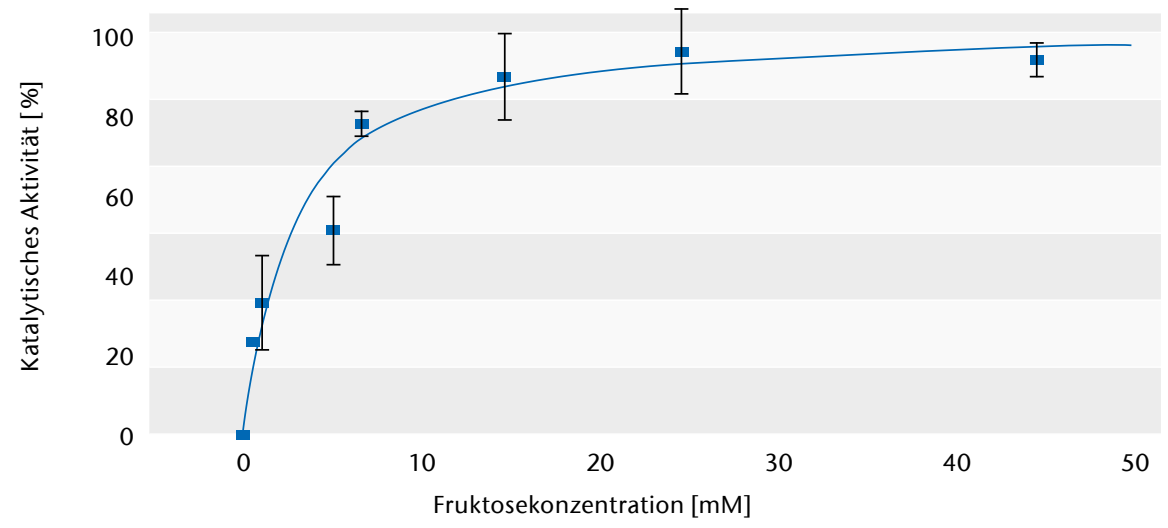

Abb. 3) Zyklovoltammogramme einer Cyt c-Monoschicht-Elektrode mit $4 \mathrm{U} / \mathrm{ml} \mathrm{FDH}$ in Lösung (20 mM KPPPuffer pH 5,0, Scanrate $2 \mathrm{mV} / \mathrm{s}$ ). (A) Cyt c-Monoschicht mit FDH in Lösung (1) und nach Zugabe von Fruktose verschiedener Konzentrationen: 0,5 mM (2), 5,0 mM (3), 15,0 mM (4), 45,0 mM (5). (B) Plot des prozentualen katalytischen Stroms erhalten bei $+200 \mathrm{mV}$ (vs. Ag/AgCl, $1 \mathrm{M} \mathrm{KCl}$ ), als Funktion der Fruktosekonzentration. Hier verwendet: kommerzielle FDH (Sigma Aldrich). Mittelwerte aus 4 Wiederholungsmessungen $(n=4)$.

$\mathrm{pH}$ 7,0 festgestellt werden konnte. Die Abhängigkeit des katalytischen Stroms von der Fruktosekonzentration ist Abb. $3 \mathrm{~B}$ zu entnehmen. Der Verlauf ist prinzipiell ähnlich dem bei $\mathrm{pH} 7$, jedoch kann hier ein deutlich höherer Km-Wert von 2,6 mM abgeschätzt werden. Zusammenfassend ist festzustellen, dass der ET-Weg im neutralen $\mathrm{pH}$-Bereich im Vergleich zum sauren Milieu deutlich höhere Ströme bei kleineren Substratkonzentrationen zulässt. Gleich ist in beiden $\mathrm{pH}$-Bereichen die Limitierung der $\mathrm{Ab}$ fuhr der Elektronen vom reduzierten Enzym bei hohen Fruktosekonzentrationen.

Untersuchungen mit auf Cyt c-Monoschichten gebundener FDH. Die Immobilisierung von FDH auf Cyt cMonoschichten wurde hier basierend auf adsorptiven Wechselwirkungen aufgrund unterschiedlicher Ladungen der beiden Biomoleküle erreicht. Dieses Prinzip wurde bereits in frühe- 
Umsetzung solcher Architekturen, unter Erhalt der Elektronentransfereigenschaften von Cyt $c$ konnte schon mehrfach gezeigt werden (Spricigo et al. 2008, Wegerich et al. 2011, Feifel et al. 2014). Cyt $c$ ist somit nicht nur Reaktionspartner der FDH, sondern fungiert auch als elektronleitender "Draht" durch die kompakte Multischichtstruktur. Im Hinblick auf den Aufbau von Multischichten ist die Wahl eines negativ geladenen Polymers wie DNA sinnvoll. Sie dient hierbei nur als strukturelles Bauelement, dessen negative Ladung in Interaktion mit dem positiv geladenen Cyt $c$ ausgenutzt wird. DNA selbst ist im angewendeten Potentialbereich nicht elektroaktiv und bindet, wie zuvor durch Sarauli et al. (2009) und Wettstein et al. (2014) beschrieben, im sauren Milieu stabil elektrostatisch eine große Menge Cyt c. Die alternierende Abscheidung von DNA und einer Cyt $c / F D H-M i s c h u n g$ wurde in dieser Arbeit so durchgeführt, dass Strukturen mit 3, 5 oder 7 Multischichten entstanden sind (Au-MU/MUA-Cyt c-[DNA-Cyt c/FDH]n).

Zunächst ergaben sich jedoch die Fragestellungen, ob erstens Cyt $c$ und FDH tatsächlich co-immobilisiert werden können und ob zweitens ein ET zwischen beiden innerhalb der Multischichten möglich ist.

Um die Frage der Co-Immobilisierung zu klären, wurde hier zunächst eine SPR-Untersuchung durchgeführt. Auf einem modifizierten SPR-Sensorschip (siehe Abschnitt 3) wurden in einem Fließsystem schrittweise Schichten aufgebracht. In Abb. 4 ist die stetige Abscheidung der Biomoleküle durch eine Zunahme der "Response Units" (RU) sichtbar. Das Ansprechen im SPR wird in ersten Linie durch Anlagerung von bloßer Molekülmasse hervorgerufen, aber auch durch Veränderungen in der Lösung. Auch deshalb folgt jedem Anlagerungsschritt ein Spülschritt, um die Änderung der RU von Indexsprüngen zu bereinigen. Wie der Abbildung zu entnehmen, führt jede Biomoleküllösung zu einer eindeutigen Assoziation, gefolgt von einer vergleichsweise geringen Dissoziation der Moleküle im Spülschritt. Jedoch fällt die Assoziation der DNA deutlich geringer aus. Die Tatsache, dass nach erfolgter DNA-Abscheidung erneut ein ähnlich großes Abscheidungssignal für die Cyt c/FDH-

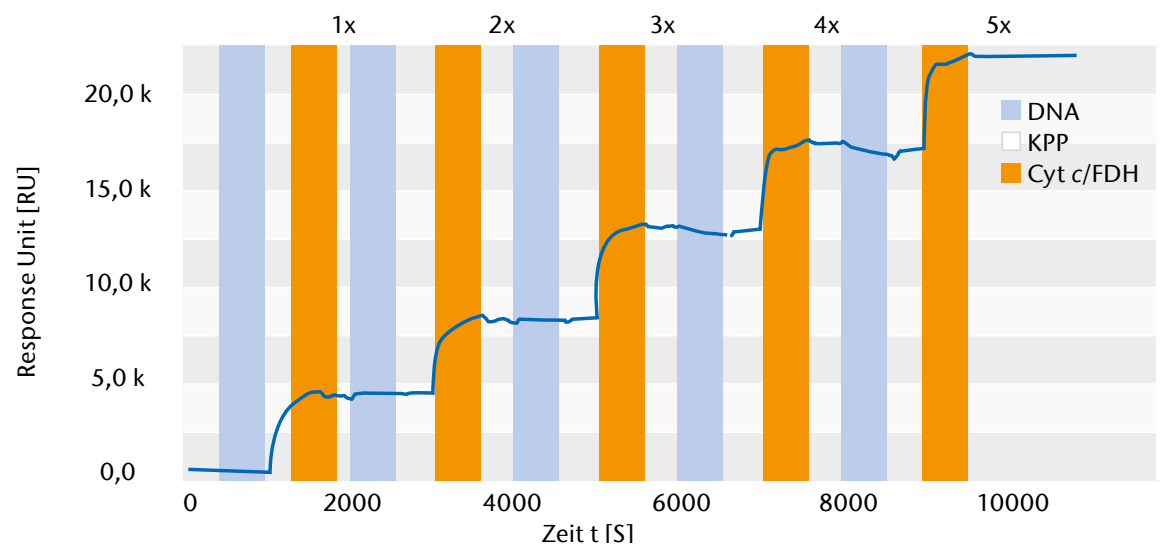

Abb. 4) SPR-Sensorgramm von [DNA-Cyt c/FDH-]Multischicht-Abscheidungen auf einem MU/MUA-modifizierten Goldchip mit einer Cyt c-Monoschicht. Cyt c/FDH-Molverhältnis: 24 : 1, Flussrate 1 ul/min, Laufpuffer 0,5 mM KPP $p H$ 5,0. Hier verwendet: nichtkommerzielle FDH aus der AG Kano.

Mischung erreicht werden kann, lässt sich als Beweis für eine hinreichende DNA-Assemblierung werten. Es kann anhand der SPR-Messung nicht aufgeklärt werden, ob und in welchem Umfang die Massenanlagerung aus der Cyt c/FDH-Mischung durch Cyt $c$ oder FDH bzw. beiden hervorgerufen wird. Spätere Untersuchungen zeigen jedoch, dass beide Proteine gemeinsam abgeschieden werden (Zyklovoltammetrie).

Für zyklovoltammetrische Messungen ist ein Wechsel der Pufferbedingungen gegenüber dem Aufbau der Multischichten notwendig. Hier wird von 0,5 mM KPP-Puffer $\mathrm{pH}$ 5,0 auf $5 \mathrm{mM} \mathrm{KPP} \mathrm{pH} \mathrm{7,0} \mathrm{gewechselt.}$ Für die Herstellung der Sensorelektroden wurde zudem eine stabilisierende Hitzebehandlung eingesetzt (Kepplinger et al. 2011).

Zunächst kann die Erhöhung der Oberflächenkonzentration von Cyt $c$ durch die Zunahme der entsprechen- den Redoxpeaks im Zyklovoltammogramm, festgestellt werden. Es lässt sich aus den Flächenintegralen der Redoxpeaks eine Oberflächenbelegung von $127 \mathrm{pmol} / \mathrm{cm}^{2}$ für eine 5-Schichtelektrode (Au-MU/MUA-Cyt $c$-[DNA - Cyt $c /$ FDH] $]_{5}$ ) bestimmen. Die Zugabe von $10 \mathrm{mM}$ Fruktose führt zu einem detektierbaren katalytischen Strom. Tab. 1 sind Werte für weitere Multischichten zu entnehmen. Eine sukzessive Zunahme sowohl der Konzentration der Redoxproteine als auch der katalytischen Ströme mit der Anzahl der aufgebrachten Schichten ist zu konstatieren. Dies ist auch ein Beweis für die gemeinsame $A b$ scheidung beider Proteine während der Herstellung. Wenn das Cyt $c / F D H$ Verhältnis weiter gesenkt wird (von 24:1 auf 5:1) dann kann der katalytische Strom noch weiter gesteigert werden (siehe Abb.5).

Damit kann in dem Multischichtsystem ein effizienter ET sichergestellt

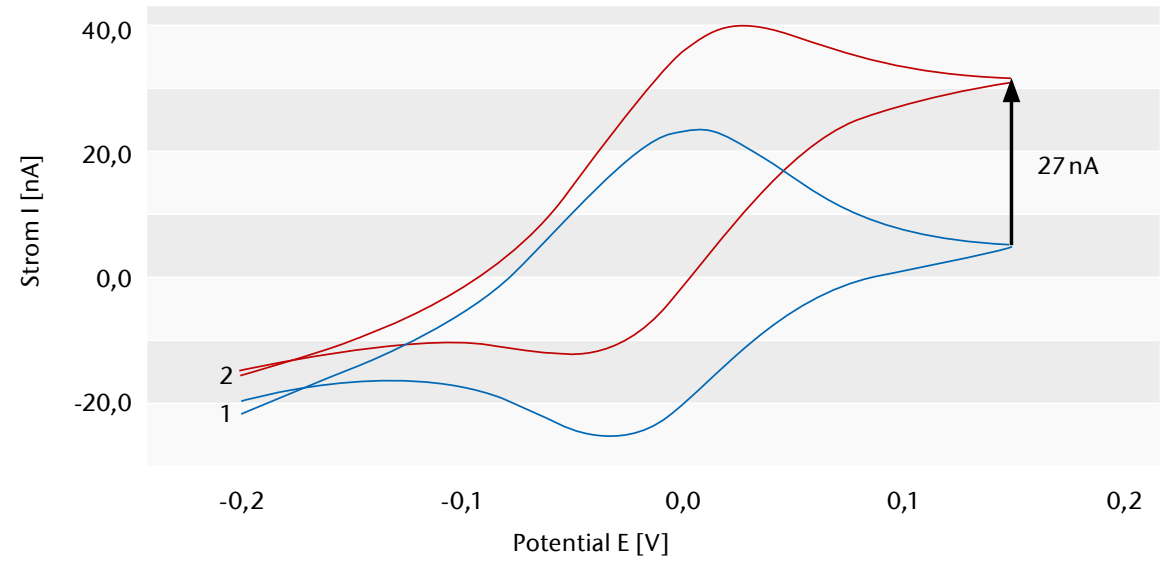

Abb. 5) Zyklovoltammogramm einer 5-Schichtelektrode (Au-MU/MUA-Cyt c-[DNA-Cyt C/FDH]5). Cyt c/FDHMolverhältnis: $5: 1,5 \mathrm{mM}$ KPP-Puffer $\mathrm{pH}$ 7,0, Scanrate $2 \mathrm{mV} / \mathrm{s}$. In Abwesenheit von Fruktose (1) und nach Zugabe von 10 mM Fruktose (2). Hier verwendet: nichtkommerzielle FDH aus der AG Kano. 
werden, und zwar sowohl durch Selbstaustausch (Cyt $c$ zu Cyt c) als auch durch Interprotein-ET (FDH zu Cyt c). In Abb. 6 ist schematisch der Elektronentransportweg dargestellt. Die FDH liefert nach Substratzugabe und erfolgter Umsetzung diese Elektronen für die Reduktion von Cyt $c$-Molekülen in unmittelbarer Umgebung. Anschließend werden Elektronen über einen Shuttle-Prozess (Cyt c-Cyt c-Elektronenaustausch) zur Elektrode abgeführt, wo im finalen Schritt Elektronen über die an der SAMSchicht gebundenen Cyt c-Moleküle einen oxidativen katalytischen Strom generieren.

Vergleicht man an dieser Stelle den hier verwendeten reinen proteinbasierten Ansatz mit bereits publizierten, in denen ein Redoxpolymer (bspw. Osmiumkomplex) verwendet wird, so findet man in beiden Ansätzen einen ETMechanismus, der auf dem „Hopping“ zwischen den Redoxzentren beruht. Die Diffusionskoeffizienten für Redoxpolymer bewegen sich in dem Bereich von $10^{-9}$ bis $10^{-11} \mathrm{~cm}^{2} \mathrm{~s}^{-1}$ und resultieren in einer Austauschrate $\left(k_{e x}\right)$ von $10^{4}$ bis $10^{6} \mathrm{M}^{-1} \mathrm{~s}^{-1}$ (Pickup et al. 1983, Sosnoff et al. 1994, O'Mullane et al. 2004). Cyt $c$ zeigt eine etwas geringere Effizienz im Austausch $\left(\mathrm{k}_{\mathrm{ex}} \sim 10^{4} \mathrm{M}^{-1} \mathrm{~s}^{-1}\right.$, nach Feifel et al. 2011), aber gewährleistet dennoch einen ausreichenden Elektronentransport um Fruktose-abhängige katalytische Ströme zu detektieren. Hierbei sei angemerkt, dass lediglich bei höheren Scanraten eine Limitierung im Elektronenaustausch der Cyt $c$-Moleküle untereinander zu verzeichnen ist (sichtbar durch abnehmende katalytische Ströme). Darüber hinaus bietet der hier gezeigte Ansatz den Vorteil, einzig auf Biomolekülen zu basieren, was im Hinblick auf sensorische Anwendungen und deren Bioverträglichkeit von Bedeutung ist.

Um die Sensitivität des Systems zu untersuchen, wurden amperometrische Messungen durchgeführt. Das 5-Multischichtsystem (Au-MU/MUACyt c-[DNA-Cyt $c / F D H]_{5}$ ) ist für das Substrat Fruktose im Bereich von $5 \mu \mathrm{M}$ bis $10 \mathrm{mM}$ sensitiv. Kleinere Konzentrationen (unterhalb $5 \mu \mathrm{M}$ ) ergeben keine detektierbaren Signale. Abb. 7 gibt einen Ausschnitt einer amperometrischen Messung wieder. Nach Zugabe des Subtrates stellt sich ein
Tab. 1: Katalytische Ströme (bestimmt bei $+200 \mathrm{mV}$ vs. Ag/AgCl, $1 \mathrm{M} \mathrm{KCl}$ ) und Cyt c-Oberflächenkonzentrationen nach Abscheidung von 3, 5 und 7 Multischichten ([DNA-Cyt c/FDH], Cyt c/FDH-Verhältnis $24: 1$ auf einer thiolmodifizierten Goldelektrode (MU/MUA).

\begin{tabular}{|c|c|c|}
\hline Schichtanzahl & $\begin{array}{c}\text { Katalytischer Strom } \\
{[\mathrm{nA}]}\end{array}$ & $\begin{array}{c}\text { Cyt c-Oberflächenkonzentration } \\
{\left[\mathrm{pmol} / \mathrm{cm}^{2}\right]}\end{array}$ \\
\hline 3 & 0,5 & 15 \\
\hline 5 & 4,4 & 127 \\
\hline 7 & 8,3 & 222 \\
\hline
\end{tabular}

stabiles, gut definiertes Signal ein. Die Konzentrationsabhängigkeit ist in Abb. 7 B zusammengefasst und zeigt eine typische Michaelis-Menten-Kinetik. Eine Sättigung ist bei niedrigen mM-Konzentration erreicht. Der apparente $\mathrm{Km}$-Wert kann mit 0,3 mM angegeben werden. Dieser Wert ähnelt stark dem Wert für frei in Lösung befindliche $\mathrm{FDH}(0,5 \mathrm{mM})$ und zeigt erneut, dass in den DNA-basierten Sensorarchitekturen, die Cyt c/FDHInteraktion limitiert ist durch den $\mathrm{Ab}$ transport der Elektronen vom reduzierten Enzym zur Elektrode.

Die Stabilität der Multischichtarchitekturen während der Messung und Lagerung wurde ebenfalls untersucht. Dabei erweisen sich die Sensorstrukturen stabil gegen mechanischen Stress, wie Rühren oder Pufferwechsel. Nach Lagerung in 0,5 mM KPP-Puffer $\mathrm{pH}$ 5,0 bei $4{ }^{\circ} \mathrm{C}$ konnte nach drei Tagen eine durchschnittliche Aktivitätsminderung um $25 \%$ und nach elf Tagen um $45 \%$ festgestellt werden. Dies zeigt, dass auch in Abwesenheit von stabilisierenden Detergenzien, FDH durch die Co-Immobilisierung hinreichend vor Denaturierungsprozessen geschützt wird.

\section{Fazit}

Es wurde die ET-Reaktion des Flavinabhängigen Enzyms FDH mit dem Redoxprotein Cyt $c$ sowohl in Lösung als auch gebunden an Oberflächen untersucht. In Lösung konnte neben einem $\mathrm{pH}$-Optimum von 4,0 ein weiterer vorteilhafter $\mathrm{pH}$ bei 7,0 festgestellt werden. Wenn Cyt $c$ gebunden an der Oberfläche vorliegt, ist ein ET mit FDH für $\mathrm{pH}$-Werte von 5,0 und 7,0 detektierbar. Gleichwohl ist der ET im neutralen $\mathrm{pH}$-Bereich effizienter. Dieses Verhalten suggeriert, dass es zwei ET-Wege gibt. Darüber hinaus zeigen die hier gemachten Untersuchungen, dass ein ET zwischen Cyt $c$ und FDH möglich ist, auch wenn ein Protein oberflächengebunden vorliegt.

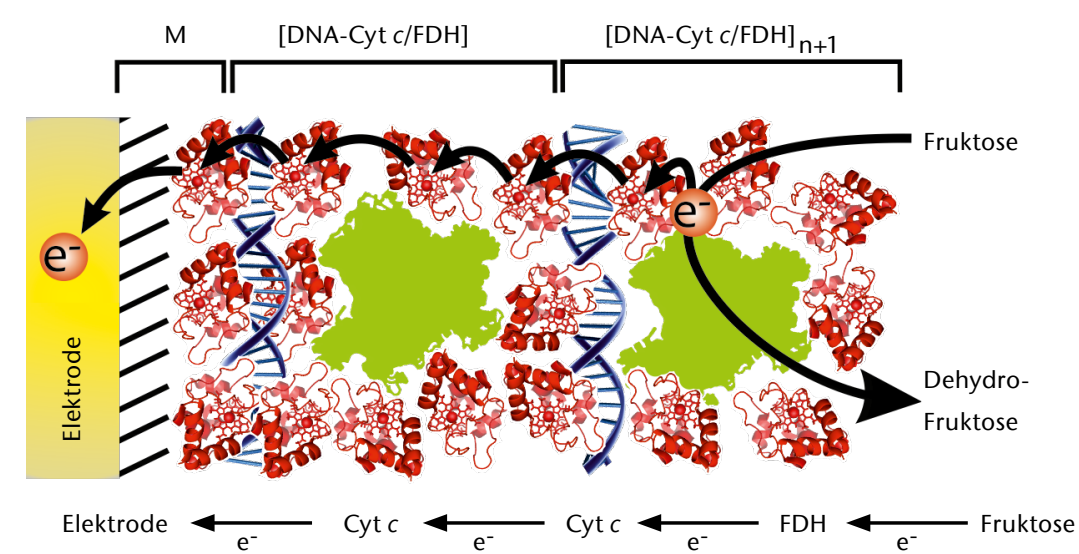

Abb. 6) Schematische Illustration der Elektronentransferschritte in einer Cyt c/FDH-Multischichtelektrode in Anwesenheit von Fruktose. 


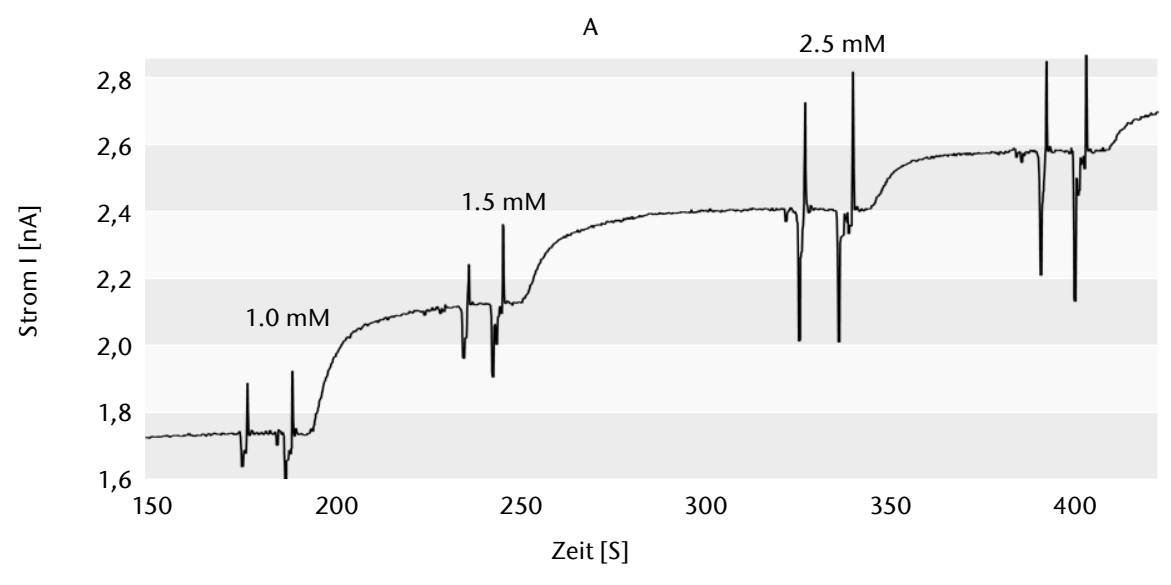

B

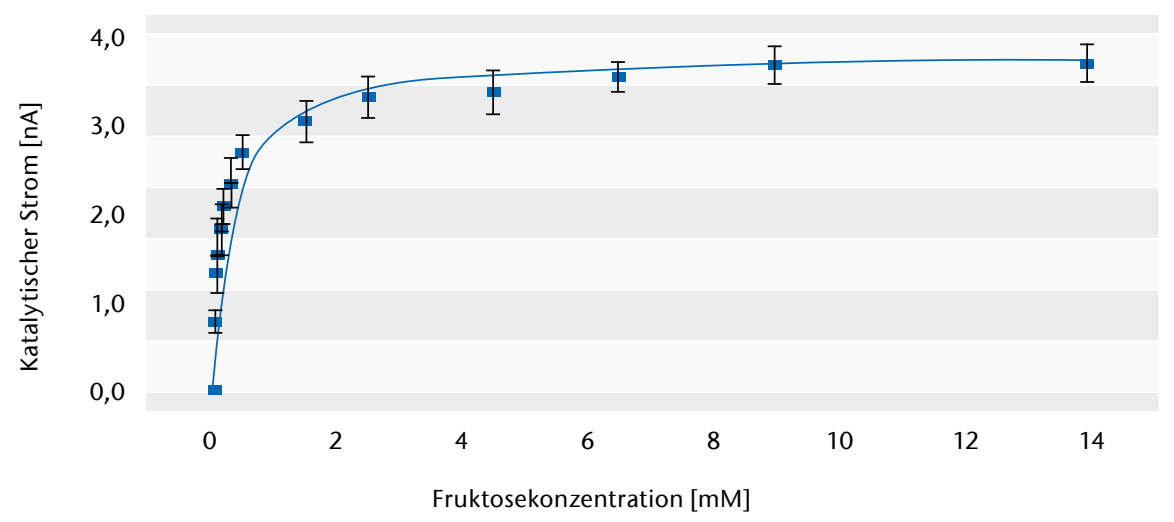

Abb. 7) Elektrochemische Charakterisierung einer 5-Schichtelektrode (Au-MU/MUA-Cyt c-[DNA-Cyt C/FDH]5) in $5 \mathrm{mM}$ KPP-Puffer $\mathrm{pH} 7,0$ und mit einem Potential von $+200 \mathrm{mV}$ (vs. Ag/AgCl, $1 \mathrm{M} \mathrm{KCl}$ ). (A) Amperometrische Messung der modifizierten Elektrode unter schrittweiser Zugabe steigender Substratkonzentrationen im Bereich von 0,01 mM bis $21 \mathrm{mM}$ Fruktose. (B) Plot der katalytischen Ströme im Substratbereich von 0,01 mM bis 14,0 mM Fruktose. Mittelwerte aus 3 Wiederholungsmessungen $(n=3)$.

Es konnte im Weiteren gezeigt werden, dass eine ET-Reaktion auch dann noch möglich ist, wenn beide Proteine an der Elektrodenoberfläche fixiert werden. Während die direkte Immobilisierung von FDH auf Cyt c-Monoschichten lediglich in eine moderate katalytische Aktivität mündete, konnte durch die Konstruktion von Multischichtarchitekturen mit Hilfe von DNA eine deutliche Steigerung in den katalytischen Strömen erzielt werden. Dabei ließ sich eine Erhöhung der Sensorsignale mit zunehmender Anzahl der Multischichten erreichen. Die Sensitivität dieser Multischichtelektroden kann somit während der Herstellung gesteuert werden.

Die hier erzeugten 3D-Strukturen, einzig aus Biomolekülen aufgebaut, haben ein hohes Potential zur Anwendung in sensorischen Fragestellungen und bieten eine Reihe weiterer interessanter Vorteile. So können bspw. mehrere unterschiedliche Enzyme in solch eine Struktur eingebunden werden, um weitere natürliche Reaktionskaskaden zu imitieren (Dronov et al. 2008, Lisdat

\section{LITERATUR}

Ameyama M, Shinagawa E, Matsushita K, Adachi O (1981) D-fructose dehydrogenase of Gluconobacter industrius: purification, characterization, and application to enzymatic microdetermination of D-fructose. Journal of Bacteriology 145(2):814-823

Armstrong FA, Hill HAO, Walton NJ (1988) Direct electrochemistry of redox proteins. Accounts of Chemical Research 21(11):407-413. doi: 10.1021/ar00155a004 Bard AJ, Stratmann M (2007], c2002) Encyclopedia of electrochemistry. Wiley-VCH, Weinheim. ISBN: 3527610421

Bassi AS, Lee E, Zhu J-X (1998) Carbon paste mediated, amperometric, thin film biosensors for fructose monitoring in honey. Food Research International 31(2):119-127. doi: 10.1016/S0963-9969(98)00071-4

Berg JM, Tymoczko JL, Stryer L (2012) Biochemistry, 7. ed., international ed., [Nachdr.]. Freeman Palgrave Macmillan, New York, NY. ISBN: 978142927635

Cooney MJ, Svoboda V, Lau C, Martin G, Minteer SD (2008) Enzyme catalysed biofuel cells. Energy Environ. Sci. 1(3):320. doi: 10.1039/b809009b

Dronov R, Kurth DG, Mohwald H, Spricigo R, Leimkuhler S, Wollenberger U, Rajagopalan KV, Scheller FW, Lisdat F (2008) Layer-by-layer arrangement by protein-protein interaction of sulfite oxidase and cytochrome c catalyzing oxidation of sulfite. I Am Chem Soc 130(4):1122-1123. doi: $10.1021 /$ ja0768690

Feifel SC, Kapp A, Lisdat F (2014) Electroactive Nanobiomolecular Architectures of Laccase and Cytochrome $c$ on Electrodes: Applying Silica Nanoparticles as Artificial Matrix. Langmuir 30(19):5363-5367. doi: 10.1021/ la500460n

Feifel SC, Kapp A, Ludwig R, Gorton L, Lisdat F (2013) Electrocatalytically active multi-protein assemblies using nanoscaled building blocks. RSC Adv 3(10):34283437. doi: 10.1039/C2RA22819]

Feifel SC, Lisdat F (2011) Silica nanoparticles for the layer-by-layer assembly of fully electro-active cytochrome c multilayers. J Nanobiotechnol 9(59). doi: 10.1186/1477-3155-9-59

Feifel SC, Ludwig R, Gorton L, Lisdat F (2012) Catalytically Active Silica Nanoparticle-Based Supramolecular Architectures of Two Proteins - Cellobiose Dehydrogenase and Cytochrome $\mathrm{c}$ on Electrodes. Langmuir 28(25):9189-9194. doi: 10.1021/la301290z

Ferapontova EE, Lo Gorton (2005) Direct electrochemistry of heme multicofactor-containing enzymes on alkanethiol-modified gold electrodes. Bioelectrochemistry 66(1-2):55-63. doi: 10.1016/j. bioelechem.2004.04.004

Ge B, Lisdat F (2002) Superoxide sensor based on cytochrome $c$ immobilized on mixed-thiol SAM with a new calibration method. Analytica Chimica Acta 454(1):53-64. doi: 10.1016/S0003-2670(01)01545-8

Ikeda T, Matsushita F, Senda M (1991) Amperometric fructose sensor based on direct bioelectrocatalysis. Biosensors and Bioelectronics 6(4):299-304. doi: 10.1016/0956-5663(91)85015-O

lin W, Wollenberger U, Bier FF, Makower A, Scheller FW (1996) Electron transfer between cytochrome $c$ and copper enzymes. Bioelectrochemistry and Bioenergetics 39(2):221-225. doi: 10.1016/0302-4598(95)01879-4

lin W, Wollenberger U, Kärgel E, Schunck W-H, Scheller FW (1997) Electrochemical investigations of the intermolecular electron transfer between cytochrome C and NADPH-cytochrome P450-reductase. Journal of Electroanalytical Chemistry 433(1-2):135-139. doi: 10.1016/S0022-0728(97)00272-6

Kamitaka Y, Tsujimura S, Setoyama N, Kajino T, Kano K (2007) Fructose/dioxygen biofuel cell based on direct electron transfer-type bioelectrocatalysis. Phys Chem Chem Phys 9(15):1793-1801. doi: 10.1039/b617650j 
Katz E, Willner I (2003) A biofuel cell with electrochemically switchable and tunable power output. I Am Chem Soc 125(22):6803-6813. doi: 10.1021/ja034008v

Kawai S, Goda-Tsutsumi M, Yakushi T, Kano K, Matsushita K (2013) Heterologous overexpression and characterization of a flavoprotein-cytochrome c complex fructose dehydrogenase of Gluconobacter japonicus NBRC3260. Appl Environ Microbiol 79(5):1654-1660. doi: 10.1128/ AEM.03152-12

Kawai S, Yakushi T, Matsushita K, Kitazumi Y, Shirai O, Kano K (2014) The electron transfer pathway in direct electrochemical communication of fructose dehydrogenase with electrodes. Electrochemistry Communications 38:28-31. doi: 10.1016/j.elecom.2013.10.024

Kepplinger C, Lisdat F, Wollenberger U (2011) Cytochrome c/Polyelectrolyte multilayer investigated by E-QCM D: Effect of temperature on the assembly structure. Langmuir 27(13):8309-8315. doi: 10.1021/la200860p

Khan GF, Kobatake E, Shinohara H, Ikariyama Y, Aizawa M (1992) Molecular interface for an activity controlled enzyme electrode and its application for the determination of fructose. Anal. Chem. 64(11):1254-1258. doi 10.1021/ac00035a011

Khan GF, Shinohara H, Ikariyama Y, Aizawa M (1991) Electrochemical behaviour of monolayer quinoprotein adsorbed on the electrode surface. Journal of Electroanalytical Chemistry and Interfacial Electrochemistry 315(1-2):263-273. doi: 10.1016/0022-0728(91)80075-2

Kinnear KT, Monbouquette HG (1997) An amperometric fructose biosensor based on fructose dehydrogenase immobilized in a membrane mimetic layer on gold. Anal Chem 69(9):1771-1775. doi: 10.1021/ac960665

Lisdat F, Dronov R, Möhwald H, Scheller FW, Kurth DG (2009) Self-assembly of electro-active protein architec tures on electrodes for the construction of biomimetic single chains. Chem Commun 2009(3):274-283. doi: 10.1039/b813559b

Marcinkeviciene J, Johansson G (1993) Kinetic studies of the active sites functioning in the quinohemoprotein fructose dehydrogenase. FEBS Letters 318(1):23-26. doi: 10.1016/0014-5793(93)81319-U

Murata K, Suzuki M, Kajiya K, Nakamura N, Ohno H (2009) High performance bioanode based on direct electron transfer of fructose dehydrogenase at gold nanoparticle-modified electrodes. Electrochemistry Communications 11(3):668-671. doi: 10.1016/j. elecom.2009.01.011

'Mullane AP, Macpherson JV, Unwin PR, CerveraMontesinos J, Manzanares JA, Frehill F, Vos JG (2004) Measurement of Lateral Charge Propagation in [Os(bpy) 2 (PVP) n CI]Cl Thin Films. A Scanning Electrochemical Microscopy Approach. J. Phys. Chem. B 108(22):72197227. doi: $10.1021 /$ jp049500

Pickup PG, Murray RW (1983) Redox conduction in mixed-valent polymers. J. Am. Chem. Soc. 105(14):4510-4514. doi: 10.1021/ja00352a002

Sarauli D, Ludwig R, Haltrich D, Gorton L, Lisdat F (2012) Investigation of the mediated electron transfer mechanism of cellobiose dehydrogenase at cytochrom c-modified gold electrodes. Bioelectrochem 87:9-14. doi: 10.1016/j.bioelechem.2011.07.003

Sarauli D, Tanne J, Schäfer D, Schubart IW, Lisdat F (2009) Multilayer electrodes: Fully electroactive cyt c on gold as a part of a DNA/protein architecture. Electrochem Comm 11(12):2288-2291. doi: 10.1016/j. elecom.2009.10.012

Sarauli D, Tanne I, Xu C, Schulz B, Trnkova L, Lisdat F (2010) Insights into the Formation of Polyaniline Sulfonate/Cytochrome c Multilayer Electrodes: Contributions of Polyelectrolyte Properties. Phys Chem Chem Phys 2(42):14271-14277. doi: 10.1039/COCP00793E
Sarauli D, Wettstein C, Peters K, Schulz B, FattakhovaRohlfing D, Lisdat F (2015) Interaction of Fructose Dehydrogenase with a Sulfonated Polyaniline. Application for Enhanced Bioelectrocatalysis. ACS Catal 5(4):2081-2087. doi: 10.1021/acscatal.5b00136 Sasaki Y, Sugihara T, Osakai T (2011) Electron transfer mediated by membrane-bound d-fructose dehydrogenase adsorbed at an oil/water interface. Anal Biochem 417(1):129-135. doi: 10.1016/j.ab.2011.06.003

Song S, Clark RA, Bowden EF, Tarlov MJ (1993) Characterization of cytochrome c/alkanethiolate structures prepared by self-assembly on gold. J. Phys. Chem. 97(24):6564-6572. doi: 10.1021/j100126a037

Sosnoff CS, Sullivan M, Murray RW (1994) Electron SelfExchange Rates in a Site-Dilutable Osmium Bipyridine Redox Polymer. J. Phys. Chem. 98(51):13643-13650. doi: $10.1021 / \mathrm{j} 100102 \mathrm{a} 034$

Spricigo R, Dronov R, Lisdat F, Leimkühler S, Scheller FW, Wollenberger U (2009) Electrocatalytic sulfite biosensor with human sulfite oxidase co-immobilized with cytochrome $\mathrm{c}$ in a polyelectrolyte-containing multilayer. Anal Bioanal Chem 393(1):225-233. doi: $10.1007 / s 00216-008-2432-y)$

Spricigo R, Dronov R, Rajagopalan KV, Lisdat F, Leimkühler S, Scheller FW, Wollenberger U (2008) Electrocatalytically functional multilayer assembly of sulfite oxidase and cytochrome c. Soft Matter 4(5):972. doi: $10.1039 / \mathrm{b} 717694 \mathrm{e}$

Stieger KR, Feifel SC, Lokstein H, Lisdat F (2014) Advanced unidirectional photocurrent generation via cytochrome $c$ as reaction partner for directed assembly of photosystem I. Phys Chem Chem Phys 16(29):1566715674. doi: 10.1039/c4cp00935e

Tamaki T (2012) Enzymatic Biofuel Cells Based on ThreeDimensional Conducting Electrode Matrices. Top Catal 55(16-18):1162-1180. doi: 10.1007/s11244-012-9895-y

Taniguchi I, Toyosawa K, Yamaguchi H, Yasukouch K (1982) Voltammetric response of horse heart cytochrome $\mathrm{c}$ at a gold electrode in the presence of sulfur bridged bipyridines. Journal of Electroanalytical Chemistry and Interfacial Electrochemistry 140(1):187-193. doi: 10.1016/0368-1874(82)85313-6

Tkac J, Svitel J, Vostiar I, Navratil M, Gemeiner P (2009) Membrane-bound dehydrogenases from Gluconobacter sp.: interfacial electrochemistry and direct bioelectrocatalysis. Bioelectrochemistry 76(1-2):53-62 doi: 10.1016/j.bioelechem.2009.02.013

Tominaga M, Nomura S, Taniguchi I (2009) D-fructose detection based on the direct heterogeneous electron transfer reaction of fructose dehydrogenase adsorbed onto multi-walled carbon nanotubes synthesized on platinum electrode. Biosens Bioelectron 24(5):11841188. doi: 10.1016/j.bios.2008.07.002

Tominaga M, Shirakihara C, Taniguchi I (2007) Direct heterogeneous electron transfer reactions and molecular orientation of fructose dehydrogenase adsorbed onto pyrolytic graphite electrodes. Journal of Electroanalytical Chemistry 610(1):1-8. doi: 10.1016/j. jelechem.2007.06.014

van GELDER B, SLATER EC (1962) The extinction coefficient of cytochrome c. Biochim Biophys Acta 58:593-595

Wegerich F, Turano P, Allegrozzi M, Möhwald $\mathrm{H}$, Lisdat F (2011) Electroactive Multilayer Assemblies of Bilirubin Oxidase and Human Cytochrome C Mutants: Insight in Formation and Kinetic Behavior. Langmuir 27(7):4202-4211. doi: 10.1021/la104964z

Wettstein C, Kyne C, Doolan AM, Möhwald H, Crowley PB, Lisdat F (2014) Study of Cytochrome c-DNA Interaction - Evaluation of Binding Sites on the Redox Protein. Nanoscale 6(22):13779-13786. doi: 10.1039/c4nr05301j

Wettstein C, Möhwald H, Lisdat F (2012) Coupling of pyrroloquinoline quinone dependent glucose dehydrogenase to (cytochrome c/DNA)-multilayer systems on electrodes. Bioelectrochem 88:97-102. doi: 10.1016/j. bioelechem.2012.06.003
Wu Y, Hu S (2007) Biosensors based on direct electron transfer in redox proteins. Microchim Acta 159(1-2): 1-17. doi: 10.1007/s00604-007-0749-4.

\section{AUTOREN}

Prof. Dr. habil. Fred Lisdat

Dr. Christoph Wettstein

Daniel Schäfer

Biosystemtechnik

Technische Hochschule Wildau

Prof. Dr. Kenji Kano

Division of Applied Life Sciences Graduate School of Agriculture Kyoto University, Sakyo

Prof. Dr. Ulla Wollenberge Institut für Biochemie und Biologie Universität Potsdam

E-Mail für Korrespondenz: fred.lisdat@th-wildau.de

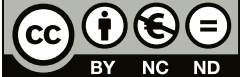

